\title{
Detecção molecular e análise filogenética de vírus respiratório sincicial bovino (BRSV) em swabs e tecido pulmonar de bovinos adultos ${ }^{1}$
}

\author{
Helena Gallicchio Domingues ${ }^{2}$, Fernando Rosado Spilki ${ }^{3 *}$ e Clarice Weis Arns ${ }^{2}$
}

\begin{abstract}
Domingues H.G., Spilki F.R. \& Arns C.W. 2011. [Molecular detection and phylogenetic analysis of bovine respiratory syncytial virus (BRSV) in swabs and lung tissues of adult cattle.] Detecção molecular e análise filogenética de vírus respiratório sincicial bovino (BRSV) em swabs e tecido pulmonar de bovinos adultos. Pesquisa Veterinária Brasileira 31(11):961-966. Laboratório de Microbiologia Molecular, Instituto de Ciências da Saúde, Universidade Feevale, Rodovia RS-239, 2755, Novo Hamburgo, RS 93352-000, Brazil. E-mail: fernandors@feevale.br

Bovine respiratory syncytial viruses virus (BRSV) is one of the etiologic agents of pneumonia in young cattle. Few studies have been made aiming detection of the virus in samples collected from adult animals, especially those asymptomatic bovines. However, it is assumed that infections in these groups may occur mostly asymptomatic and this would be an important mechanism for maintaining of BRSV in herds. In this study, the goal was to conduct an analysis of the occurrence of asymptomatic infections by BRSV in lung samples $(n=68)$ and nasal swabs (209) taken from adult animals collected in abattoirs from Southern and Southeastern Brazil respectively, to detect via polymerase chain reaction the occurrence of infected animals in populations of adult cattle. The samples that resulted positive (6) on RT-PCR were subsequently subjected to cutting with restriction enzymes and sequencing for genetic characterization ( 2 samples). All samples belongs to subgroup B of BRSV, which is reported as the one circulating in Brazil. The results obtained demonstrate that BRSV may be present in samples taken from adult animals, which is in agreement the hypothesis that infections in adults run in a sub-clinical way that may be of importance as a maintenance mechanism of the virus in bovine herds.
\end{abstract}

INDEX TERMS: Bovine respiratory syncytial virus, asymptomatic cattle, virus isolation, molecular phylogenetic analysis.

RESUMO.- 0 vírus respiratório sincicial bovino (BRSV) é um dos agentes etiológicos de pneumonias em bovinos jovens. Poucos estudos foram realizados visando à detecção do agente em amostras coletadas de animais adultos, e em especial de bovinos assintomáticos. No entanto, presume-se que as infecções ocorridas nestes grupos possam ocorrer em sua maioria de forma assintomática e este seria um mecanismo importante para manutenção do BRSV nos

\footnotetext{
${ }^{1}$ Recebido em 21 de abril de 2011.

Aceito para publicação em 16 de agosto de 2011.

${ }^{2}$ Laboratório de Virologia Animal, Instituto de Biologia, Universidade Estadual de Campinas (Unicamp), Cx. Postal 6109, Campinas, SP 13083970, Brasil.

${ }^{3}$ Laboratório de Microbiologia Molecular, Instituto de Ciências da Saúde, Universidade Feevale, Rodovia RS-239, 2755, Novo Hamburgo, RS 93352-000, Brasil. *Autor para correspondência: fernandors@feevale.br
}

rebanhos. No presente estudo, o objetivo foi realizar uma análise da prevalência de infecções assintomáticas pelo BRSV em pulmões ( $\mathrm{n}=68$ ) e swabs nasais (209) coletados de bovinos adultos coletadas em frigoríficos da região Sul e Sudeste respectivamente, no sentido de detectar por intermédio de reação da polimerase em cadeia qual a taxa de animais infectados em populações de animais adultos onde não ocorram sinais clínicos da infecção. As amostras positivas à RT-PCR (6) foram posteriormente submetidas ao corte com enzimas de restrição (REA) e sequenciamento para caracterização genética do gene $\mathrm{F}$ ( 2 das amostras). Todas as amostras se enquadram no subgrupo B de BRSV, o grupo circulante no Brasil conforme estudos anteriores. Os resultados obtidos demonstram que o BRSV pode estar presente em amostras obtidas de animais sadios, reforçando a hipótese de que infecções subclínicas 
fazem parte do mecanismo de manutenção do vírus nos rebanhos.

TERMOS DE INDEXAÇÃO: Vírus respiratório sincicial bovino, bovinos assintomáticos, isolamento viral, análise filogenética molecular.

\section{INTRODUÇÃO}

$\mathrm{O}$ vírus respiratório sincicial bovino (BRSV), um membro do gênero Morbillivirus, subfamília Pneumovirinae, família Paramyxoviridae, ordem Mononegavirales, é associado a pneumonias em bovinos jovens (Easton et al. 2004, Valarcher et al. 2007). A caracterização de isolados de BRSV com monoclonais e por filogenia molecular permite classificá-las em 3 subgrupos nomeados A, B e AB (Furze ate al., 1994). Destes, o subgrupo $B$ foi o único relatado até o presente momento no Brasil, ainda que um número bastante reduzido de isolados esteja disponível para análise (Spilki et al. 2006).

As manifestações clínicas da infecção pelo BRSV podem estar relacionadas a diferentes fatores relacionados ao agente, ao animal e ao ambiente: a virulência das cepas pode ser variável (Schrijver et al. 1998); a ocorrência de coinfecções bacterianas ou parasitárias (Ellis et al. 2009, Gulliksen et al. 2009, Brodersen et al. 2010). A susceptibilidade dos bovinos também pode variar, especialmente quanto ao seu arcabouço genético relacionado à imunidade celular (Antonis et al. 2006). Fatores ambientais, relacionadas à má qualidade do ar e presença de alérgenos ou ainda condições climáticas podem induzir ao aparecimento de sinais clínicos evidentes em animais infectados (Gershwin et al. 1990, Kalina et al. 2006, Gershwin et al. 2008).

Presume-se que as infecções ocorridas em animais adultos possam ocorrer em sua maioria de forma assintomática e este seria um mecanismo importante para manutenção do BRSV nos rebanhos (De Jong et al. 1996, Van Der Poel et al. 1997, Hägglund et al. 2006). Bovinos adultos, todavia, também podem desenvolver quadros de pneumonia após a infecção pelo BRSV (Paccaud \& Jacquier 1970). Em vacas leiteiras foram relacionadas com quedas na produção leiteira e a vacinação prévia ao período de lactação interfere positivamente na produção e nos valores de pico de lactação dos animais (Van der Poel et al. 1995, Beaudeau et al. 2010). Todavia, a maioria das infecções com sinais clínicos mais evidentes e quadros graves ocorre no primeiro ano de vida e apenas excepcionalmente após a entrada na fase adulta (Uttenthal et al. 2000, Hägglund et al. 2006, Valarcher et al. 2007, Brodersen et al. 2010).

No presente estudo, o objetivo foi realizar uma análise da ocorrência de infecções assintomáticas pelo BRSV em swabs e fragmentos de tecido pulmonar de bovinos adultos coletadas em frigoríficos da região Sul e Sudeste, no sentido de inferir por metodologias de detecção molecular (RT-PCR) qual a taxa de animais infectados em populações de animais adultos onde não ocorram sinais clínicos da infecção. As amostras positivas à RT-PCR foram posteriormente submetidas ao corte com enzimas de restrição e sequenciamento para caracterização genética.

\section{MATERIAL E MÉTODOS}

\section{Swabs nasais e amostras de tecido pulmonar}

Foram obtidas e analisadas 277 amostras provenientes de bovinos. Deste total, 209 amostras foram swabs de secreções nasais de animais vivos de rebanhos de bovinos de corte localizados na região oeste do estado de São Paulo. Os swabs foram acondicionados em tubos de poliestireno de 1,5mL livres de RNAses e DNAses, contendo $500 \mu \mathrm{L}$ de tiocianato de guanidina-fenol (TRIzol $\AA$, Invitrogen TM Carlsbad, Califórnia, USA). As 68 amostras restantes foram colhidas no Estado do Rio Grande do Sul, sendo 68 amostras provenientes de animais de abatedouros sem sintomatologia de doença respiratória, dentre essas amostras, 34 provinham de secreções nasais colhidas previamente ao abate e, 34 fragmentos de pulmões dos mesmos animais. Todas as amostras foram armazenadas a $-80^{\circ} \mathrm{C}$ até o processamento.

\section{Células e vírus}

Foram utilizadas células da linhagem contínua Chicken Embryo Related (CER) cultivadas em garrafas de $75 \mathrm{~cm}^{2}$ (Corning), na concentração de $1,3 \times 10^{5}$ células/mL (concentração inicial) em meio essencial mínimo Eagle (MEM-Cultilab®, Campinas, SP) com $10 \%$ de soro fetal bovino (SFB, Sigma Chemical Company®), por 24 horas a $37^{\circ} \mathrm{C}$. Foram utilizadas também células da linha-

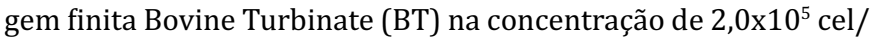
$\mathrm{ml}$, gentilmente cedidas pelo Prof. Dr. Lars Erik Larsen, Instituto Dinamarquês de Veterinária. Essas células foram cultivadas e mantidas com os mesmos parâmetros descritos acima para a linhagem celular CER.

Foram mantidas e utilizadas como controles positivos em todas as etapas amostras pertencentes aos diferentes subgrupos de BRSV. Como representante do subgrupo A, o isolado BRSV Lehmkuhl 375 (Valarcher ey al. 2000), proveniente dos Estados Unidos e adquirido através da American Type Culture Collection (ATCC). A amostra BRSV-25-BR e BRSV-108-BR isoladas no Laboratório de Virologia Animal/IB/Unicamp foram utilizadas como representante do subgrupo B (Arns et al. 2003, Almeida et al. 2005, Spilki et al. 2006), e um isolado europeu cedido pelo Dr. Lars Erik Larsen (BRSV-9402022), como controle positivo do subgrupo AB (Larsen et al. 1998). Todos os isolados foram propagados pela inoculação dos cultivos celulares com 0,01a 0,1 DICC 50/ $\mathrm{mL}$. Após duas horas de adsorção viral a $37^{\circ} \mathrm{C}$, o inóculo foi removido e foram adicionados $25 \mathrm{~mL}$ de MEM por garrafa. A incubação foi realizada a $37^{\circ} \mathrm{C}$, e as culturas foram observadas diariamente em microscópio invertido (Axiovert $100^{\mathrm{tm}}$, Carl Zeiss $囚$ ) para observação do efeito citopático (ECP) característico do BRSV, isto é, formação de sincício e arredondamento celular.

As amostras foram armazenadas em tubos de $1,5 \mathrm{~mL}$ e $50 \mathrm{~mL}$, respectivamente, e mantidas a $-70^{\circ} \mathrm{C}$ até o momento do uso.

\section{Extração de RNA viral}

O RNA do material de campo, bem como as amostras isoladas e os controles de células, foi submetido à extração viral utilizando-se diferentes protocolos, os quais variaram conforme a amostra utilizada. As monocamadas celulares não infectadas utilizadas como controles negativos da RT-PCR, bem como os cultivos infectados com amostras padrão que apresentavam aproximadamente $20 \%$ de ECP, foram raspadas utilizando-se Cell Scraper II (Costar), e a suspensão obtida foi transferida para tubos de $15 \mathrm{~mL}$ (Costar) e centrifugada a $720 \times g$ durante 12 min.. 0 sedimento foi então dissolvido com $1 \mathrm{~mL}$ de TRIzol@. A mistura foi transferida para tubos de 1,5mL estéreis e livres de RNAses, e mantida por $10 \mathrm{~min}$. em temperatura ambiente. As amostras de secreções nasais que estavam em meio de transporte foram descongeladas e a seguir 
centrifugadas a $3.000 \times \mathrm{g}$ durante $10 \mathrm{~min}$. Após retiraram-se os swabs coletores e acrescentaram-se $12,5 \mu$ de glicogênio. Aproximadamente $200 \mathrm{mg}$ de cada amostra de fragmento de pulmão foram macerados e dissolvidos com $1 \mathrm{~mL}$ de TRIzol $^{\circledR}$ e $12,5 \mu \mathrm{L}$ de glicogênio e mantidos por $10 \mathrm{~min}$. à temperatura ambiente. Em seguida, foram acrescentados a todas as amostras $200 \mu \mathrm{L}$ de clorofórmio gelado para cada $\mathrm{mL}$ de TRIzol@ utilizado, seguido de agitação vigorosa (vortex) durante 15 segundos e repouso por 3 min. à temperatura ambiente. Após realizou-se centrifugação a $4^{\circ} \mathrm{C}$ durante $20 \mathrm{~min}$. a $12.000 \mathrm{x} \mathrm{g}$, e a fase transparente resultante, contendo o RNA total, foi transferida para outro tubo de $1,5 \mathrm{~mL}$ estéril e livre de RNAses. A seguir acrescentou-se v/v de isopropanol gelado, que foi seguido de repouso durante $10 \mathrm{~min} . \mathrm{a}-20^{\circ} \mathrm{C}$. Para a precipitação completa do RNA total o material foi centrifugado por $20 \mathrm{~min}$. a $12.000 \mathrm{xg}$ a $4^{\circ} \mathrm{C}$. 0 sobrenadante resultante foi então descartado e o sedimento lavado com $1 \mathrm{~mL}$ de etanol $70^{\circ} \mathrm{em}$ água contendo $0,1 \%$ de dietilpirocarbonato (DEPC), e foi deixado reagir por $10 \mathrm{~min}$. em gelo. Uma nova centrifugação foi realizada a 12.000 x $g$ a $4^{\circ} \mathrm{C}$ durante $5 \mathrm{~min}$., em seguida descartou-se o sobrenadante e procedeu-se novamente à centrifugação, utilizando-se os mesmos parâmetros acima citados. 0 etanol remanescente foi retirado com auxílio de ponteira, e o sedimento foi diluído em $25 \mu \mathrm{L}$ de água com DEPC e mantido $10 \mathrm{~min}$. a $55^{\circ} \mathrm{C}$ para inibir a ação de prováveis moléculas de RNAses presentes.

\section{Síntese de cDNA}

Para a síntese do cDNA utilizou-se o kit comercial Superscript II para RT-PCR (Invitrogen ${ }^{\mathrm{TM}}$ Carlsbad, Califórnia, USA), seguindo recomendações do fabricante. Para um volume final de $11 \mu \mathrm{l}$ acrescentou-se a um tubo de $200 \mu \mathrm{L}, 1 \mu \mathrm{L}$ de iniciadores randômicos e $2 \mu \mathrm{g}$ de RNA total (a diferença para $10 \mu \mathrm{l}$ foi completada com água tratada com DEPC). A mistura foi incubada a $72^{\circ} \mathrm{C}$ por 10 min. Após, acrescentaram-se $2 \mu \mathrm{l}$ de DTT, $1 \mu \mathrm{l}$ de dNTP e $4 \mu \mathrm{l}$ de tampão $5 \mathrm{x}$ da enzima e $1 \mu \mathrm{l}$ da enzima Transcriptase reversa-RT. Após, o material foi incubado a $40^{\circ} \mathrm{C}$ por 60 minutos e $96^{\circ} \mathrm{C}$ por $10 \mathrm{~min}$.

\section{Reação de RT-PCR para amplificação dos genes G e F de BRSV}

Fragmentos do gene G de BRSV foram amplificados para triagem das amostras positivas e posterior ensaio de corte com enzimas de restrição. Amostras positivas na RT-PCR para o gene G foram submetidas a uma nova reação visando a amplificação do gene $\mathrm{F}$ e os amplicons posteriormente submetidos a sequenciamento gênico. Para um volume final de $50 \mu \mathrm{L}$ foram acrescentados em tubos de $200 \mu \mathrm{L}$ estéreis os seguintes reagentes: $5 \mu \mathrm{L}$ tampão PCR 10X [200mM Tris-HCl (pH 8,4), 500mM KCl]; $1 \mu \mathrm{ldNTP}$ $10 \mathrm{mM} ; 1 \mu \mathrm{L}$ do iniciador B5A (10pmol) e $1 \mu \mathrm{L}$ iniciador B6A para o gene $\mathrm{G}$ (Vilcek et al. 1994) ou $1 \mu \mathrm{L}$ do iniciador B1 (10pmol) e $1 \mu \mathrm{L}$ do iniciador B2A para o gene F (Vilcek et al. 1994); 0,5 $\mu \mathrm{L}$ da enzima Platinum DNA polimerase (Pfx DNA Polimerase; Invitrogen ${ }^{\mathrm{TM}}$ Carlsbad, Califórnia, USA), contendo $2,5 \mathrm{U} / \mu \mathrm{L} ; 2 \mu \mathrm{L}$ de $\mathrm{MgCl} 2 ; 3 \mu \mathrm{L}$ cDNA e água destilada estéril com DEPC, até atingir o volume final. A mistura foi aquecida por 3 min a $94^{\circ} \mathrm{C}$ para desnaturação. A amplificação foi realizada em um termociclador PCR System 9700 (GeneAmp, Applied Biosystems $®$ ). 0 ciclo termal consistiu em denaturação a $94^{\circ} \mathrm{C}$ durante $60 \mathrm{~s}$., anelamento a $5^{\circ} \mathrm{C}$ durante $60 \mathrm{~s}$. e extensão a $72^{\circ} \mathrm{C}$ por 90 s. Foram realizados 32 ciclos de amplificação. 0 último ciclo de extensão foi prolongado por $10 \mathrm{~min}$. Após a reação as amostras foram diluídas 1:6 em tampão de corrida da amostra (0,25\% de azul de bromofenol, $40 \%$ p/v de sacarose em água), aplicadas em gel de agarose $1 \%$ contendo brometo de etídeo e separadas por eletroforese a $100 \mathrm{~V}$ por 1 hora. Os fragmentos obtidos foram visualizados e fotografados sob transiluminação ultravioleta.

\section{Análise de amplicons do gene G por restrição enzimática (REA)}

A seleção das enzimas foi realizada com base nas sequências obtidas no Genbank (http://www.ncbi.nlm.nih.gov/genbank/) para o gene G dos diferentes subgrupos existentes de BRSV. Essas sequencias foram submetidas à análise utilizando o programa Nebcutter 2.0 (http://tools.neb.com/NEBcutter2/), que forneceu uma lista de enzimas capazes de clivar e destas selecionadas aquelas capazes de permitir a distinção entre os subgrupos de BRSV. Dentre as enzimas disponíveis foram selecionadas as seguintes: Hinfl, PstI e EconI, que discriminan os subgrupos A, B e B/ $\mathrm{AB}$ respectivamente. Os amplicons obtidos das amostras positivas no PCR para o gene G foram então clivados utilizando-se a metodologia descrita por Sambrook et al. (1989) e seguindo instruções do fabricante. Em linhas gerais, a solução de reação foi preparada em tubos de $0,2 \mathrm{~mL}$, cada um contendo $17.5 \mu \mathrm{l}$ do amplicom, $0.5 \mu \mathrm{l}$ da enzima $(10 \mathrm{U} / \mu \mathrm{l})$ e $2 \mu \mathrm{l}$ de tampão de reação $(50 \mathrm{mM}$ Tris- $\mathrm{HCl}$, $10 \mathrm{mM} \mathrm{MgCl}_{2}, 50 \mathrm{mM} \mathrm{NaCl}$ ). Em seguida, as reações foram incubadas a $37^{\circ} \mathrm{C}$ durante $90 \mathrm{~min}$. Os produtos obtidos após a técnica na REA foram separados por eletroforese a $90 \mathrm{~V}$ por $90 \mathrm{~min}$. em gel de agarose a $1 \%$ contendo brometo de etídeo, visualizados e fotografados sob transiluminação ultravioleta após eletroforese em gel de agarose a $1 \%$ contendo de etídeo e, em seguida, os perfis de restrição enzimática obtidos foram analisados.

\section{Sequenciamento nucleotídico parcial do gene $\mathbf{F}$}

Os amplicons gerados nas RT-PCRs foram purificados com o produto comercial GFX ${ }^{\mathrm{tm}}$ PCR DNA and Gel Band Purification Kit (GE Healthcare, Buckingham, Reino Unido), seguindo orientações do fabricante. Utilizou-se para o sequenciamento o BigDye terminator cycle sequencing ready reaction kit (Perkin-Elmer Applied Biosystems, Foster city, USA), cuja reação consistiu de da adição de $2 \mu \mathrm{L}$ de Big Dye; $2 \mu \mathrm{L}$ do tampão Save Money $5 \mathrm{x} ; 1 \mathrm{pmol}$ de cada iniciador senso e antisenso em reações separadas; 1 ou $2 \mu \mathrm{L}$ de cada amostra, dependendo da intensidade da banda gerada com os produtos purificados, para um volume final de $10 \mu \mathrm{L}$. A mistura foi aquecida a $92^{\circ} \mathrm{C}$ por $1 \mathrm{~min}$. e 30 ciclos de $96^{\circ} \mathrm{C}$ por $30 \mathrm{~s} ; 50^{\circ} \mathrm{C}$ por $15 \mathrm{~s} \mathrm{e} 60^{\circ} \mathrm{C}$ por $4 \mathrm{~min}$. seguido de resfriamento até $4^{\circ} \mathrm{C}$ até retirada do termociclador. As amostras foram precipitadas utilizando $30 \mu \mathrm{L}$ água MilliQ ${ }^{\circledR}$ livre de DNAses e $60 \mu \mathrm{L}$ de isopropanol P.A., mantidas em temperatura ambiente por 15 minutos, centrifugadas a $20000 \mathrm{x} \mathrm{g} \mathrm{a} 17^{\circ} \mathrm{C}$ por $25 \mathrm{~min}$. 0 sobrenadante foi descartado e $150 \mu \mathrm{L}$ de isopropanol $75 \%$ foram adicionados. Novamente as amostras foram centrifugadas a $20000 \mathrm{x} \mathrm{g} \mathrm{a} 17^{\circ} \mathrm{C}$ por $10 \mathrm{~min}$. e secas. A sequência de nucleotídeos foi determinada através de um sequenciador automático de DNA (ABI PRISM 310 Genetic Analyzer, Perkin-Elmer Applied Biosystems, Foster city, USA).

\section{Análise filogenética}

0 alinhamento das sequências nucleotídicas foi realizado com o aplicativo ClustalW, versão 1.83 (Thompson 2002). A reconstrução filogenética foi realizada pelo método de "neighbor-joining", Kimura-2 parâmetros, através do programa de computador MEGA 4 (Tamura et al. 2007) As sequências obtidas foram comparadas com sequências nucleotídicas homólogas de outros isolados de BRSV obtidas no GenBank (http://www.ncbi.nlm.nih.gov/genbank/).

\section{Detecção molecular do BRSV}

RESULTADOS

Foram detectadas 6 amostras positivas para BRSV utilizando a técnica de RT-PCR para o gene G, onde se observou a presença de fragmentos de $603 \mathrm{pb}$. As amostras detecta- 
das como positivas foram nomeadas $404,804,5810,3610$, 4110,4910 . As amostras positivas 404 e 804 eram provenientes de swabs nasais de animais do estado de São Paulo, e as amostras $3610,4110,4910$ e 5810 foram obtidas de pulmões de bovinos provenientes do estado do Rio Grande do Sul. Estas mesmas amostras foram também positivas para amplificação dos genes F e SH.

\section{Análise por REA dos amplicons obtidos na RT-PCR do gene $\mathbf{G}$}

Todas as seis amostras detectadas por RT-PCR foram submetidas à técnica de REA para os amplicons obtidos para o gene G. Para as amostras de swabs nasais o perfil de restrição enzimático observado demonstrou que a amostra 404 pertence ao subgrupo B. Na REA, a amostra 804 revelou um perfil intermediário, podendo estar ainda relacionada ao subgrupo A, o que foi refutado posteriormente no sequenciamento nucleotídico e análise filogenética. Os perfis de restrição enzimáticos para as amostras de pulmão positivas sugeriram que as amostras 3610, 4110, 4910 e 5810 pertencem também ao subgrupo $B$.

\section{Caracterização filogenética molecular}

Foram sequenciados os fragmentos correspondentes ao gene $\mathrm{G}$ das amostras detectadas (404 e 804 provenientes de swabs nasais de animais do estado de São Paulo). Das amostras restantes não foi possível, mesmo depois de repetidas tentativas, obter material em qualidade adequada que permitisse a análise das sequências nucleotídicas com confiabilidade. Das amostras para as quais foi possível a obtenção de sequências de boa qualidade, ambas apresentaram elevada identidade ( $>95 \%$ ) com o fragmento homólogo analisado das amostras protótipo do subgrupo B, 22060 e BOVX. Os resultados da análise filogenética molecular podem ser observados na Figura 1.

\section{DISCUSSÃO}

Foram detectadas 6 amostras positivas para a presença de BRSV em animais adultos sem sinais clínicos de doença respiratória dentre as quais duas amostras de secreções nasais oriundas do estado de São Paulo e quatro amostras de fragmentos pulmonares provenientes do estado do Rio Grande do Sul. Deste modo, genoma do BRSV estava pre-

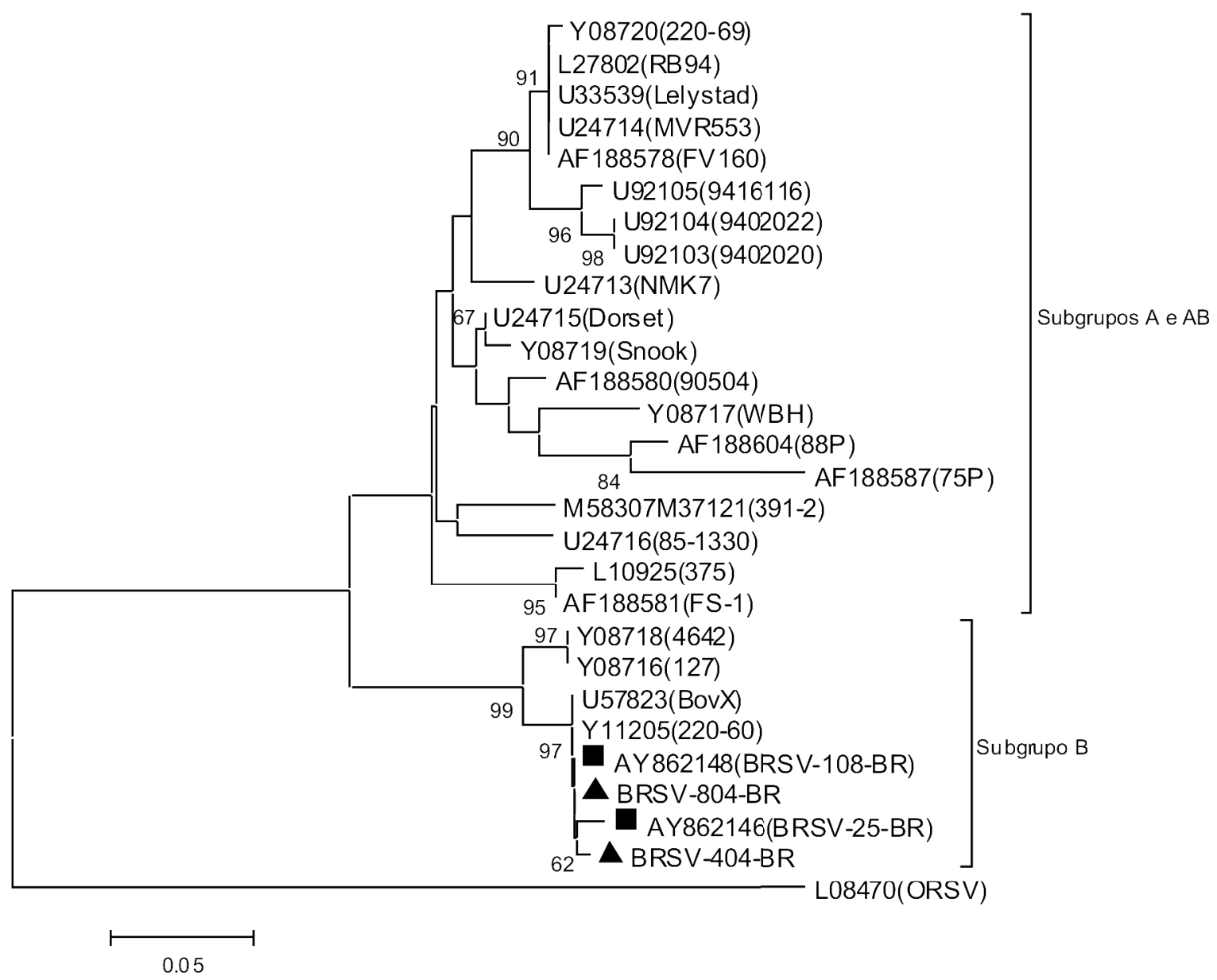

Fig. 1. Relações filogenéticas entre amostras de BRSV brasileiras e de outros países. A história evolutiva foi inferida usando o método de "Neighbor-joining". Apenas valores de "bootstrap" superiores a 50 são mostrados. A análise envolveu 28 sequências de nucleotídeos e 218 posições nucleotídicas foram avaliadas. As amostras descritas neste trabalho estão assinaladas com um triângulo $(\boldsymbol{\Delta})$ e fica clara sua proximidade com amostras brasileiras descritas anteriormente, assinaladas com um quadrado (घ). 
sente em 2,16\% (6/277) do total das amostras analisadas. Estes resultados vão de encontro com a hipótese gerada a partir de evidências sorológicas, de que o BRSV se mantém nos rebanhos bovinos em infecções persistentes subclínicas em um pequeno número de indivíduos adultos e por reinfecções esporádicas de animais previamente soropositivos (Van Der Poel et al. 1997). No presente estudo, a amostragem foi feita a partir de rebanhos diferentes, o que não permite inferir como seria a prevalência em determinado rebanho. Estudos futuros, envolvendo uma análise longitudinal da infecção em rebanhos fechados, adotando as técnicas de detecção aqui utilizadas, poderiam elucidar em que medida estas infecções de animais adultos efetivamente contribuem para a manutenção do BRSV nos rebanhos. Em estudo utilizando reação em cadeia da polimerase com transcrição reversa (RT-PCR) a partir de amostras de quatro animais sem sinais clínicos em contato com animais doentes em um surto de pneumonia por BRSV, as 4 amostras resultaram negativas e os autores inferiram que o vírus deve estar ausente em animais sem manifestações clínicas (Vilcek et al. 1994), o que não está de acordo com o presente estudo e com outros trabalhos que analisam a dinâmica de anticorpos produzidos em rebanhos sem história recente de doença ocasionada pelo BRSV (Uttenthal et al. 2000). De fato, a dinâmica da produção de anticorpos em rebanhos fechados permite inferir que as reinfecções pelo vírus são relativamente comuns, mesmo em animais adultos e na ausência de sinais clínicos (Schrijver et al. 1996, Uttenthal et al. 2000).

O uso da técnica de REA, com vistas a uma melhor definição dos possíveis subgrupos de BRSV a serem encontrados em amostras clínicas é promissor, pela rapidez e facilidade de realização quando comparada, por exemplo, ao sequenciamento nucleotídico. Todavia, deve-se considerar a dificuldade em diferenciar alguns isolados entre os subgrupos B e AB. A amostra 804, que foi considerada como possivelmente pertencente ao subgrupo $\mathrm{AB}$ pela técnica de REA, após o sequenciamento a amostra agrupou claramente no subgrupo B já que, conforme observado por outros autores, substituição de um único nucleotídeo pode induzir alterações no padrão de digestão (Valentova et al. 2005).

É digno de nota que até o presente todos os exemplares de BRSV detectados no Brasil neste em outros trabalhos tenham se enquadrado no subgrupo B que, após ser isolado no Reino Unido nos anos 1970, nunca mais foi observado em outros países à exceção do Brasil (Nettleton et al. 2003, Spilki et al. 2006). As possíveis consequências práticas deste fato, em especial para a profilaxia da infecção, já que todas as vacinas comercializadas no país trazem vírus do subgrupo A, devem ser estudadas com experimentos controlados em bovinos ou em modelos animais (Duncan Jr et al. 1993, Schrijver 1998, Spilki \& Arns 2010).

De modo geral, pode-se concluir a partir achados do presente estudo que: i) as técnicas de RT-PCR aqui utilizadas têm sucesso em atestar a presença de fragmento genômicos específicos do BRSV em amostras biológicas e podem ser utilizadas para novos estudos sobre a disseminação deste agente nos rebanhos bovinos; ii) a análise de amplicons de RT-PCR para o gene G de BRSV pela técnica de REA não apresentou resultados conclusivos quando da classificação das amostras nos diferentes subgrupos sendo necessária a análise filogenética das amostras de BRSV para uma correta classificação dos genomas detectados. Não obstante, propõe-se a utilização da técnica de REA como uma ferramenta auxiliar para detecção de variações genéticas pontuais entre amostras pertencentes a um mesmo subgrupo de BRSV.

Agradecimentos.- HGD e FRS foram bolsistas de doutorado da FAPESP durante a realização deste estudo. FRS e CWA são Bolsistas de Produtividade do CNPq.

\section{REFERÊNCIAS}

Almeida R.S., Spilki F.R., Roehe P.M. \& Arns C.W. 2005. Detection of Brazilian bovine respiratory syncytial virus strain by a reverse transcriptase-nested-polymerase chain reaction in experimentally infected calves. Vet. Microbiol. 105:131-135.

Antonis A.F.G., Claassen E.A.W., Hensen E.J., Groot R.J.D., Groot-Mijnes J.D.F.D., Schrijver R.S. \& Van Der Most R.G. 2006. Kinetics of antiviral CD8 T cell responses during primary and post-vaccination secondary bovine respiratory syncytial virus infection. Vaccine 24:1551-1561.

Arns C.W., Campalans J., Costa S.C.B., Domingues H.G., D’Arce R.C.F. \& Almeida R.S. 2003. Characterization of bovine respiratory syncytial virus isolated in Brazil. Braz. J. Med. Biol. Res. 36:213-218.

Beaudeau F., Björkman C., Alenius S. \& Frössling J. 2010. Spatial patterns of Bovine Corona Virus and Bovine Respiratory Syncytial Virus in the Swedish beef cattle population. Acta Vet. Scand., Article 52.

Brodersen B.W. 2010. Bovine respiratory syncytial virus. Vet. Clin. North Am., Food Anim. Pract. 26:323-333.

De Jong M.C.M., Van Der Poel W.H.M., Kramps J.A., Brand A. \& Van Oirschot J.T. 1996. Quantitative investigation of population persistence and recurrent outbreaks of bovine respiratory syncytial virus on dairy farms. Am. J. Vet. Res. 57:628-633.

Domingues H.G., Campalans J., Almeida R.S., Coswig L.T. \& Arns C.W. 2002. Dot-enzyme linked immunosorbent assay as an alternative technique for the detection of bovine respiratory syncytial virus (BRSV) antibodies. Vet. Res. 33:397-404.

Duncan Jr R.B. \& Potgieter L.N.D. 1993. Antigenic diversity of respiratory syncytial viruses and its implication for immunoprophylaxis in ruminants. Vet. Microbiol. 37:319-341.

Easton A.J., Domachowske J.B. \& Rosenberg H.F. 2004. Animal pneumoviruses: Molecular genetics and pathogenesis. Clin. Microbiol. Rev. 17:390-412.

Ellis J.A. 2009. Update on viral pathogenesis in BRD. Animal Health Research Reviews/Conference of Research Workers in Animal Diseases 10:149-153.

Furze J., Wertz G., Lerch R. \& Taylor G. 1994. Antigenic heterogeneity of the attachment protein of bovine respiratory syncytial virus. J. General Virol. 75:363-370.

Gershwin L.J. 2007. Bovine respiratory syncytial virus infection: Immunopathogenic mechanisms. Animal Health Research Reviews/Conference of Research Workers in Animal Diseases 8:207-213.

Gershwin L.J., Berghaus L.J., Arnold K., Anderson M.L. \& Corbeil L.B. 2005. Immune mechanisms of pathogenetic synergy in concurrent bovine pulmonary infection with Haemophilus somnus and bovine respiratory syncytial virus. Vet. Immunol. Immunopathol. 107:119-130.

Gershwin L.J., Dungworth D.L., Himes S.R. \& Friebertshauser K.E. 1990. Immunoglobulin E responses and lung pathology resulting from aerosol exposure of calves to respiratory syncytial virus and Micropolyspora faeni. Int. Archs Allergy Appl. Immunol. 92:293-300.

Gershwin L.J., Gunther R.A., Hornof W.J. \& Larson R.F. 2008. Effect of infection with bovine respiratory syncytial virus on pulmonary clearance of an inhaled antigen in calves. Am. J. Vet. Res. 69:416-422. 
Gulliksen S.M., Jor E., Lie K.I., Løken T., Åkerstedt J. \& Østerås O. 2009. Respiratory infections in Norwegian dairy calves. J. Dairy Sci. 92:51395146.

Hägglund S., Hjort M., Graham D.A., Öhagen P., Törnquist M. \& Alenius S. 2007. A six-year study on respiratory viral infections in a bull testing facility. Vet. Journal 173:585-593.

Hägglund S., Svensson C., Emanuelson U., Valarcher J.F. \& Alenius S. 2006. Dynamics of virus infections involved in the bovine respiratory disease complex in Swedish dairy herds. Vet. Journal 172:320-328.

Kalina W.V., Anderson M.L. \& Gershwin L.J. 2006. Alternaria aerosol during a bovine respiratory syncytial virus infection alters the severity of subsequent re-infection and enhances IgE production. Comp. Immunol. Microbiol. Infect. Dis. 29:138-156.

Larsen L.E., Tjørnehøj K., Viuff B., Jensen N.E. \& Uttenthal Å. 1999. Diagnosis of enzootic pneumonia in Danish cattle: Reverse transcription-polymerase chain reaction assay for detection of bovine respiratory syncytial virus in naturally and experimentally infected cattle. J. Vet. Diagn. Invest. 11:416-422.

Larsen L.E., Uttenthal A., Arctander P., Tjørnehøj K., Viuff B., Røntved C., Rønsholt L., Alexandersen S. \& Blixenkrone-Møller M. 1998. Serological and genetic characterisation of bovine respiratory syncytial virus (BRSV) indicates that Danish isolates belong to the intermediate subgroup: No evidence of a selective effect on the variability of G protein nucleotide sequence by prior cell culture adaption and passages in cell culture or calves. Vet. Microbiol. 62:265-279.

Nettleton P.F., Gilray J.A., Caldow G., Gidlow J.R., Durkovic B. \& Vilcek S. 2003. Recent isolates of Bovine respiratory syncytial virus from Britain are more closely related to isolates from USA than to earlier British and current mainland European isolates. J. Vet. Med. B 50:196-199.

Paccaud M.F. \& Jacquier C. 1970. A Respiratory syncytial virus of bovine origin. Archiv für die gesamte Virusforschung 30:327-342.

Schrijver R.S., Daus F., Kramps J.A., Langedijk J.P.M., Buijs R., Middel W.G.J., Taylor G., Furze J., Huyben M.W.C. \& Van Oirschot J.T. 1996a. Subgrouping of bovine respiratory syncytial virus strains detected in lung tissue. Vet. Microbiol. 53:253-260.

Schrijver R.S., Langedijk J.P.M., Middel W.G.J., Kramps J.A., Rijsewijk F.A.M. \& Van Oirschot J.T. 1998. A bovine respiratory syncytial virus strain with mutations in subgroup-specific antigenic domains of the $G$ protein induces partial heterologous protection in cattle. Vet. Microbiol. 63:159-175.

Schrijver R.S., Langedijk J.P.M., Van Der Poel W.H.M., Middel W.G.J., Kramps J.A. \& Van Oirschot J.T. 1996b. Antibody responses against the G and F proteins of bovine respiratory syncytial virus after experimental and natural infections. Clin. Diagn. Lab. Immunol. 3:500-506.

Spilki F.R., Almeida R.S., Domingues H.G., D’Arce R.C.F., Ferreira H.L., Campalans J., Costa S.C.B. \& Arns C.W. 2006. Phylogenetic relation ships of Brazilian bovine respiratory syncytial virus isolates and molecular homology modeling of attachment glycoprotein. Virus Res. 116:30-37.

Spilki F.R., de Almeida R.S. \& Arns C.W. 2010. Antibody responses in mice after immunization with inactivated bovine respiratory syncytial virus using different adjuvants. Ciência Rural 40:2332-2337.

Tamura K., Dudley J., Nei M. \& Kumar S. 2007. MEGA4: Molecular evolutionary genetics analysis (MEGA) software version 4.0. Molecular Biology and Evolution 24:1596-1599.

Thompson J.D., Gibson T.J. \& Higgins D.G. 2002. Multiple sequence alignment using ClustalW and Clustal X. Current Protocols in Bioinformatics/ Editoral Board, Andreas D. Baxevanis ... [et al.] Chapter 2.

Tippmann H.F. 2004. Analysis for free: comparing programs for sequence analysis. Briefings in Bioinformatics 5:82-87.

Uttenthal A., Larsen L.E., Philipsen J.S., Tjørnehøj K., Viuff B., Nielsen K.H. \& Nielsen T.K. 2000. Antibody dynamics in BRSV-infected Danish dairy herds as determined by isotype-specific immunoglobulins. Vet. Microbiol. 76:329-341.

Valarcher J.F., Schelcher F. \& Bourhy H. 2000. Evolution of bovine respiratory syncytial virus. J. Virology 74:10714-10728.

Valarcher J.F. \& Taylor G. 2007. Bovine respiratory syncytial virus infection. Vet. Res. 38:153-180.

Valentova V., Antonis A.F.G. \& Kovarcik K. 2005. Restriction enzyme analysis of RT-PCR amplicons as a rapid method for detection of genetic diversity among bovine respiratory syncytial virus isolates. Vet. Microbiol. 108:1-12.

Van der Poel W.H., Mourits M.C., Nielen M., Frankena K., Van Oirschot J.T. \& Schukken Y.H. 1995. Bovine respiratory syncytial virus reinfections and decreased milk yield in dairy cattle. Vet. Quarterly 17:77-81.

Van Der Poel W.H.M., Langedijk J.P.M., Kramps J.A., Middel W.G.J., Brand A. \& Van Oirschot J.T. 1997. Serological indication for persistence of bovine respiratory syncytial virus in cattle and attempts to detect the virus. Archs Virology 142:1681-1696.

Vilcek S., Elvander M., Ballagi-Pordany A. \& Belak S. 1994. Development of nested PCR assays for detection of bovine respiratory syncytial virus in clinical samples. J. Clin. Microbiol. 32:2225-2231. 